\title{
DESENVOLVIMENTO MORAL: NOVAS PERSPECTIVAS DE ANÁLISE
}

\section{New Perspectives for the Study of Moral Development}

\author{
AliaBarrios Nunes ${ }^{1}$ \\ AngelaUchoaBranco ${ }^{2}$
}

\section{Resumo}

O presente artigo aborda o desenvolvimento moral a partir dos pressupostos e conceitos teóricos da perspectiva sociocultural construtivista, a qual enfatiza o caráter sistêmico e integrado do desenvolvimento moral do indivíduo, e a dimensão interativa e contextual envolvida no desenvolvimento de crenças e valores morais. Ao longo do texto, são apresentados e discutidos pressupostos e conceitos teóricos que enfatizam a importância dos processos afetivos para o desenvolvimento moral, que ocorre em contextos culturais específicos. A perspectiva adotada considera a integração entre cognição, emoção e ação, analisando as várias dimensões fundamentais para a compreensão do desenvolvimento moral. Algumas considerações sobre a relação entre desenvolvimento moral e educação são apontadas, enfatizando a necessidade de pensar essa relação a partir do caráter sistêmico e holístico do desenvolvimento humano.

Palavras-chave: Desenvolvimento moral; Crenças; Valores; Socialização.

\section{Abstract}

This paper focus on the study of moral development from a sociocultural constructivist perspective. This approach emphasizes the systemic nature of moral development, and considers the interactive and contextual dimensions of developmental processes giving rise to moral beliefs and values. We present and discuss conceptual and theoretical assumptions and issues, as we underline the role of affective processes in moral development, contextualized in specific cultural environments. The perspective adopted takes into account the different aspects or dimensions of moral development, and the integration of affection, cognition and action. From a systemic and holist viewpoint of human development, we argue for the need to better understand the relationships between moral development and education.

Keywords: Moral development; Beliefs; Values; Socialization.

\footnotetext{
1 Aluna do Programa de Pós-Graduação em Desenvolvimento Humano e Saúde, Instituto de Psicologia, Universidade de Brasília-UnB. Graduada em Psicologia pela Universidade de Havana, Cuba. e-mail: aliabarrio@gmail.com

2 Professora associada, Instituto de Psicologia, Universidade de Brasília-UnB. Pós-Doutorado na Duke University e na University of North Carolina, Estados Unidos. e-mail: ambranco@terra.com.br

2 Autora agradece o CNPq pelo apoio (Bolsa de Pesquisa).
} 
A moral, ao longo da história, tem despertado o interesse, tanto da filosofia, como de diversas áreas do conhecimento. Como apontado por Lustosa (2005), a moral tem sido objeto de estudo de filósofos clássicos, como Aristóteles e Platão, e filósofos contemporâneos, como Tugendhat (1997). Recentemente, questões referentes à ética e à moral vêm sendo discutidas em variados campos da ciência, em especial pela sociologia e pela psicologia, ciências que tentam apreender o caráter social e subjetivo dos atos morais (e.g. DeVries \& Zan, 1998; Freitag, 1997; Hoffman, 2000; Lapsley \& Narvaez, 2004; La Taille, 1992; Puig, 1998).

O interesse pela moralidade surge, em primeiro lugar, pela sua natureza social e pela função reguladora que exerce no que tange ao convívio entre os seres humanos. Toda organização social tem uma moral, uma vez que todas as comunidades humanas são regidas por um conjunto de regras de conduta, por proibições de vários tipos cuja transgressão acarreta sanções socialmente organizadas (La Taille, 2006). No entanto, por trás deste conjunto de regras existem crenças e valores sociais construídos culturalmente ao longo da história de cada comunidade. Em todas as sociedades, das mais simples às mais complexas, existem sistemas morais cujas especificidades podem ser atribuídas às diferenças culturais e organizativas das diversas sociedades (Lustosa, 2005).

$\mathrm{O}$ interesse pela moral responde, em segundo lugar, à grave crise de valores da sociedade contemporânea. Crise que levanta inúmeros questionamentos e inspira amplas reflexões de legisladores, cientistas, educadores e leigos. No centro desses questionamentos e reflexões, como apontado por Lustosa (2005), situa-se a importância do desenvolvimento moral para o entendimento do desenvolvimento integral do ser humano, assim como o papel do sistema educacional em relação a ele.

O desenvolvimento moral tem sido objeto da psicologia contemporânea, entretanto isso se dá de forma ainda muito tímida e limitada. Autores construtivistas, como Piaget e Kolhberg, parecem dominar os estudos e as investigações no campo da psicologia acerca da moralidade (La Taille, 2006; Lourenço, 1998). Estes estudos enfatizam determinado aspecto do desenvolvimento humano (o cognitivo) em detrimento de outros importantes componentes do desenvolvimento moral, tais como o afeto, a motivação para agir em contextos específicos, as ações morais propriamente ditas e as práticas histórico-culturais dos grupos sociais. Em outras palavras, a tradicional ênfase inaugurada por Piaget em destacar o estudo do raciocínio e julgamento moral prossegue nos dias de hoje, sem levar em conta as inter-relações entre cognição, afeto, motivação e cultura, com isso colocando em um segundo plano a natureza sistêmica e dinâmica do desenvolvimento do indivíduo (Martins \& Branco, 2001). Martins e Branco (2001) se apóiam nos estudos e reflexões apresentados por Shweder e Much (1987) quando enfatizam a necessidade de desenvolver-se uma abordagem teórica que trate o desenvolvimento moral a partir de um enfoque amplo, no qual os aspectos cognitivos, afetivos e socioculturais sejam considerados de forma integrada e sistêmica. O enfoque fragmentado do desenvolvimento moral por exemplo, estudos que se orientam somente para a análise do julgamento moral - pode levar a uma análise parcial e não inter-relacionada das ações morais do indivíduo, que desconsidera a efetiva responsabilidade dos sujeitos em termos das ações morais, ou imorais, que de fato exibem em contextos determinados (Rey \& Martínez, 1989).

O objetivo do presente trabalho é abordar o desenvolvimento moral a partir dos pressupostos e conceitos teóricos da perspectiva sociocultural construtivista, uma vez que esta perspectiva oferece amplas e ricas possibilidades para a compreensão dos fenômenos do desenvolvimento e, no caso, para a compreensão do desenvolvimento moral. Além disso, a perspectiva sociocultural construtivista coteja as diferentes perspectivas teóricas que estudam o desenvolvimento moral, tentando ir além de forma consistente e coerente, mas sem deixar de levar em conta muitas das contribuições apresentadas por diferentes abordagens teóricas (Martins \& Branco, 2001).

\section{A natureza sociocultural do desenvolvimento moral}

Várias são as definições de moralidade. Neste texto, será adotada a perspectiva de Feitag (1997) que, baseada em Max Weber, concebe o domínio da "moral" como da ordem do sujeito, em relação dialética com o conceito de "ética", que se define por sua natureza mais social e coletiva. A natureza social do desenvolvimento moral é intrínseca ao conceito de moralidade, pois este implica necessariamente na qualidade das relações que se estabelecem entre os sujeitos (certo e errado, 
bom ou mau), e isso tem sido apontado por diversos autores (e.g. DeVries \& Zan, 1998; La Taille, 1992; Piaget, 1932/1994; Puig, 1998; Rey \& Martinez, 1989; Shweder \& Much, 1987). A moralidade não só diz respeito às relações sociais, como também tem a sua origem nos relacionamentos interpessoais. Em relação à natureza social da moralidade, Puig (1998) aponta que a construção moral é, ao mesmo tempo, individual e influenciada pela relação com os demais. Portanto, a decisão de como viver é tanto individual como social.

Em suas reflexões sobre a natureza do desenvolvimento moral e as especificidades da educação moral, Puig (1998) vai além do caráter social da moralidade e ressalta também sua natureza cultural, coincidindo com os autores que enfatizam a natureza cultural do desenvolvimento humano (e.g. Cole, 1992; Valsiner, 2007). Para Puig, os problemas morais não escapam da realidade sociocultural em que se originam, portanto, a educação moral associa-se à tarefa de ensinar o ser humano a viver no seio de uma comunidade.

As pesquisas culturais analisadas por Rogoff (2005) apontam diferentes modos de solucionar problemas morais em comunidades distintas. Estas diferenças nos preceitos morais parecem surgir de diferentes visões de mundo, assim como parecem responder a formas diferentes de organização social. No entanto, aparentemente existem alguns conceitos e preceitos obrigatórios no código moral de qualquer sociedade. Esses preceitos estão relacionados com o princípio da justiça e o princípio de evitar danos. As principais diferenças estão relacionadas à forma com que cada sociedade responde a questões como a relação entre indivíduo e sociedade, a responsabilidade do indivíduo perante a sociedade, a responsabilidade da sociedade perante o indivíduo e a garantia dos direitos individuais em uma ordem social mais justa e harmoniosa.

Vale a pena ressaltar que a existência de preceitos obrigatórios no código moral de diferentes comunidades não deve ser entendida como a existência de valores morais universais e abstratos desvinculados da realidade. Tais valores são compartilhados pelas diferentes culturas em função de sua importância para o convívio constitutivo dos seres humanos nos contextos sociais. Estes valores devem sua "universalidade" ao desenvolvimento filogenético e histórico do indivíduo e da sociedade. Como apontado por Cole (1992), o termo cultura não se restringe às diferenças culturais entre os diversos grupos humanos. A ênfase na cultura enquanto "diferenças" deixa de lado a existência da necessidade concreta e a capacidade de se desenvolver recursos gerais e específicos para habitar um meio culturalmente organizado, sendo esta a principal característica do ser humano enquanto espécie. Uma compreensão abrangente da cultura no desenvolvimento humano requer tanto a especificação dos mecanismos universais, como a especificação das formas que esses mecanismos assumem em circunstâncias históricas específicas. Ou seja, a existência de valores morais compartilhados por diferentes culturas não significa a existência de uma moral única e homogênea para os diferentes sistemas sociais que coexistem em um determinado momento da história da humanidade, mas se deve à origem e ao desenvolvimento filogenético da condição humana.

Ainda analisando diversas pesquisas culturais, Rogoff (2005) ressalta como as formas em que os adultos de uma cultura específica interferem nas questões relativas à educação das crianças variam de uma cultura para outra. Por trás dessas diversas formas de interferência existem orientações para objetivos, crenças e valores específicos para cada cultura (Valsiner, Branco \& Dantas, 1997). Por outro lado, as formas como as crianças de uma determinada cultura respondem a essas formas de interferência também estão de acordo com as orientações para objetivos, crenças e valores da cultura específica na qual elas se desenvolvem. No entanto, existe um elo comum entre as diferentes formas em que os adultos transmitem os significados da cultura coletiva: as crianças apreendem à medida que participam de práticas culturais e são orientadas pelos valores de sua comunidade. Essa participação orientada inclui esforços tanto dos parceiros sociais como das próprias crianças, que cumprem papéis ativamente centrais no seu processo de socialização. No caso específico do desenvolvimento moral, Rogoff (2005) ressalta que as crianças aprendiam a ordem moral da comunidade no decorrer dos eventos cotidianos, nos quais recebiam comentários morais, ou reações específicas, que indicavam o que era bom ou mau, certo ou errado.

A participação ativa da criança no seu desenvolvimento moral também é apontada pelos autores construtivistas. Como ressaltam Piaget (1932/1994) e La Taille (2006), é na inter-relação com o outro que a criança entra em contato com os valores 
e crenças morais e com as regras estabelecidas socialmente. Porém, esse contato não é passivo, pois o desenvolvimento do juízo moral não se resume a uma simples interiorização dos valores, princípios e regras morais. O desenvolvimento da moralidade é uma reconstrução ativa, por parte da criança, desses valores, princípios e regras. Esta reconstrução acontece a partir da atividade da criança, em contato com o meio social, e tem características específicas que dependem das estruturas mentais já construídas ao longo do seu desenvolvimento.

A questão da interiorização ou reconstrução ativa dos valores morais por parte da criança e o papel das estruturas mentais já construídas na dita interiorização nos remetem a duas idéias centrais e fundamentais da perspectiva histórico-cultural desenvolvida por Vygotsky (1960/ 1987). Este define o processo de internalização como a interiorização ativa dos conteúdos históricoculturais que se manifestam e se transmitem por meio das interações sociais dos indivíduos. Os processos de internalização geram uma série de transformações de natureza qualitativa nas funções psicológicas e devem ser entendidos a partir da experiência emocional do indivíduo, uma vez que esta experiência emocional é o fator que define o tipo de influência de uma situação determinada sobre o desenvolvimento (Vygotsky, 1994). A forma como a criança experiencia emocionalmente uma situação específica está estreitamente relacionada com o tipo de significado ou de entendimento que ela tem dessa situação específica, significado que varia em função do momento de desenvolvimento em que a criança se encontra.

A questão da internalização ou da reconstrução ativa dos significados compartilhados culturalmente é um dos pilares fundamentais da perspectiva sociocultural construtivista. Esta sintetiza, de forma criativa, as contribuições da psicologia histórico-cultural de Vygotsky e colaboradores e do construtivismo piagetiano, em relação ao papel ativo do sujeito no seu desenvolvimento (Madureira \& Branco, 2005).

A perspectiva sociocultural construtivista tenta superar a unidirecionalidade das correntes e perspectivas teóricas que enfatizam a importância do indivíduo em detrimento do contexto ou ressaltam o papel do contexto, colocando em um segundo plano a intencionalidade do sujeito psicológico (Madureira \& Branco, 2005). Fundamenta-se em uma visão holística e sistêmica do desenvolvimento humano, compreendendo-o como um processo de transformação qualitativa que acontece com base nas interações do indivíduo com seu ambiente. Dessa forma, enfatiza a natureza inerentemente social do desenvolvimento da pessoa, ressaltando a interdependência, ou a relação dialética, entre indivíduo e sociedade. Relação dialética que deve ser entendida como uma relação complexa e dinâmica, na qual indivíduo e sociedade se constituem e se transformam mutuamente. Ao mesmo tempo em que a sociedade e a cultura são importantes e participam do desenvolvimento do indivíduo, este último tem um papel ativo no seu próprio processo de desenvolvimento e nas transformações do contexto sociocultural em que se desenvolve.

Os conceitos de internalização e externalização, de fundamental importância para essa perspectiva teórica, referem-se à relação indivíduo-sociedade. O conceito de internalização se refere, especificamente, aos mecanismos e formas em que o interpsicológico se torna intrapsicológico. Este conceito tem sido proposto por vários autores e estudiosos do desenvolvimento, dentre os quais se destaca Vygotsky (1960/1987), para quem o desenvolvimento cultural da criança aparece em cena duas vezes, ou em dois planos: primeiro no plano das relações sociais, depois como categoria intrapsíquica. Vygotsky (1960/1987) reconhece o processo de internalização como um processo ativo de interiorização (ou reconstrução) dos conteúdos histórico-culturais que se manifestam e transmitem por meio das interações sociais dos indivíduos.

A externalização se refere aos mecanismos e formas pelas quais o indivíduo participa das transformações que acontecem no contexto sociocultural. Os significados e conteúdos socioculturais que foram internalizados ativamente pelo sujeito são externalizados no marco das interações sociais, introduzindo novos elementos à cultura coletiva. Como Palmieri e Branco (2004) apontam, enquanto a internalização se direciona do inter para o intra, a externalização caminha na direção inversa, do intrapsicológico para o interpsicológico. Ambos, porém, são processos simultâneos e complementares na mútua constituição indivíduo-sociedade.

Palmieri e Branco (2004) também enfatizam a inter-relação entre os processos de internalização e externalização, assim como sua importância para a compreensão da relação dialética entre a cultura coletiva e a cultura pessoal, termos 
utilizados por Valsiner $(1994,1998)$ para expressar as instâncias do social e do sujeito, em constante interação. A cultura coletiva representa os significados compartilhados pelos diferentes grupos de referência dos quais o sujeito participa. Dentre esses significados, incluem-se as normas e regras sociais, assim como as práticas da vida cotidiana. A cultura pessoal representa os significados que o indivíduo internalizou de forma ativa ("sentido", na terminologia de Vygotsky, 1934/1968), constituindo o conjunto de normas, valores, crenças e opiniões que orientam sua ação nos diferentes contextos socioculturais. A cultura pessoal é uma recriação singular da cultura coletiva que é externalizada, introduzindo novos elementos à cultura coletiva, o que permite, ao longo do tempo, romper padrões socialmente construídos.

A inter-relação entre os processos de internalização e externalização pressupõe a perspectiva bidirecional dos processos de socialização, posicionamento teórico que atribui grande importância e responsabilidade tanto à participação dos adultos como à participação das crianças nos processos interativos (Palmieri, 2003; Valsiner, 1989, 2007). Assim, a perspectiva bidirecional de socialização enfatiza os papéis ativos dos adultos e da criança de forma simultânea.

As crenças e valores morais, definidos como significados culturais compartilhados coletivamente e transmitidos no seio das interações sociais, são transmitidos de forma bidirecional. Tais crenças e valores transmitidos pelos adultos, sobretudo por aqueles com os quais a criança tem uma relação emocional significativa, são interpretados de forma ativa pela criança. Em resumo, as crenças e valores morais se constituem e transformam com o indivíduo e a sociedade, no decorrer da história da humanidade e de cada sistema social específico, em função dos processos de internalização e externalização.

\section{O sistema motivacional: crenças e valores morais}

No tópico anterior, foi ressaltado o papel fundamental da experiência emocional nos processos de internalização e externalização. Palmieri e Branco (2004) explicam que a internalização dos conteúdos culturais é orientada por diversos fatores motivacionais e afetivos, que selecionam e priorizam aspectos culturais. Esta seleção não é necessariamente intencional, mas refere-se aos significados que o indivíduo atribui aos aspectos culturais, envolvendo uma multiplicidade de sentidos pessoais. Por outro lado, a externalização do conjunto de normas, valores, crenças e opiniões que conformam a cultura pessoal de um indivíduo está estreitamente relacionada com a forma em que este experiencia uma situação e um contexto específico, dotado de uma multiplicidade de sentidos pessoais. Ou seja, cada indivíduo atribui um significado pessoal e subjetivo às experiências de seu cotidiano, assim como responde a essas experiências em função do significado pessoal que elas têm para ele.

A rede de significados pessoais reconstruídos pelo indivíduo ao longo de seu processo de desenvolvimento se organiza de forma sistêmica, fazendo parte do seu universo motivacional, que está na base de sua ação (Rossetti-Ferreira, Amorin \& Silva, 2004). Crenças e valores morais, portanto, são componentes do sistema motivacional do indivíduo e resultam dos processos de transmissão cultural que são re-significados pelo indivíduo.

$\mathrm{Na}$ perspectiva sociocultural construtivista, o universo motivacional é visto como um sistema complexo, dinâmico, subjetivo e original que está em construção e reconstrução constante. De acordo com Palmieri e Branco (2004), essa idéia de transformação está estreitamente relacionada com a introdução do termo "orientação", que enfatiza o caráter aberto e dinâmico dos conceitos de objetivos, crenças e valores.

As autoras, além de enfatizar a perspectiva dinâmica introduzida pelo termo orientação, explicam a diferença conceitual entre crenças e valores, conforme colocada por Valsiner et al. (1997). A diferença conceitual se deve, principalmente, à carga afetiva que está presente no conceito valor, que se articula mais proximamente com o conceito de meta ou objetivo. Sendo assim, o conceito "valor" se conforma como um caso especial de orientação para crença, que é mais estável em função de sua carga afetiva e do papel que desempenha nos processos de formação da identidade.

Diversos autores, como Melo (1996) e Salomão (2001), fizeram uma revisão dos conceitos de crença e valor na literatura, apontando como esses termos têm sido utilizados de formas diversas, às vezes como sinônimos e, geralmente, como entidades psicológicas relativamente estáticas e bem definidas. Melo (1996) abordou os dois termos desde a perspectiva sociocultural construtivista, destacando aspectos importantes, como o caráter 
dinâmico e, por vezes, contraditório do sistema de crenças e valores do indivíduo. Salomão (2001) também salientou a controvérsia existente em torno da definição conceitual desses dois termos e enfatizou a organização sistêmica e hierárquica das crenças e valores no sistema motivacional do indivíduo, que inclui outros elementos, tais como seus objetivos pessoais, suas necessidades, seus motivos inconscientes, as características e regras específicas do contexto e os costumes sociais.

Branco (2006) enfatiza as idéias apontadas por Valsiner et al. (1997) sobre o sistema de crenças do indivíduo, que diz respeito às reflexões, idéias ou pensamentos que ele tem sobre o mundo e as relações que o cercam. Relações que muitas vezes refletem a heterogeneidade das regras e mensagens culturais da cultura coletiva. Sendo assim, podem co-existir inconsistências em um mesmo discurso e prática social, sobretudo, em função da indeterminação dos processos de desenvolvimento. Por outro lado, essas inconsistências também refletem a emergência de novos padrões sociais, em função da participação ativa do sujeito na constante reconstrução ou re-significação da cultura coletiva.

Sintetizando, a perspectiva sociocultural construtivista entende as crenças e, em especial, os valores como elementos importantes do sistema motivacional, o qual regula as interações sociais e integra as funções psicológicas do sujeito à dinâmica social em que este se insere, em processo de contínuo desenvolvimento. As crenças e valores apresentados pelo indivíduo são co-construídos e interiorizados a partir de sua história de vida, experiências emocionais e interações constantes com o universo físico, social e simbólico que o cerca.

Crenças e valores podem orientar o comportamento do indivíduo (por meio das “orientações para objetivo" específicas, Branco \& Valsiner, 1997), proporcionando um sentido para suas ações dentro das fronteiras e limites (constraints) de sua cultura. Tais crenças e valores podem, então, ser confirmados e/ou desconfirmados diante das experiências, das práticas sociais e da visão de mundo predominante em uma época determinada. As crenças e valores do indivíduo, porém, devem ser entendidos a partir do termo "orientação", que abrange a possibilidade de transformação ou de construção e reconstrução ao longo do seu desenvolvimento. Os valores, entretanto, podem ser considerados como um caso especial de crenças, pois são mais estáveis em função de sua carga afetiva e do papel que desempenham nos processos de formação da identidade, sendo menos suscetíveis a mudanças ou re-significações. As crenças e valores do indivíduo podem se relacionar de forma conflitante em função da diversidade e da existência de contradições nas sugestões e valores culturais que envolvem o indivíduo, assim como em função das possibilidades de transformação de suas próprias crenças e valores.

A integração sistêmica, dinâmica e complexa das crenças e valores morais no universo motivacional do indivíduo, que está na base de sua ação, é de vital importância para o estudo e compreensão do desenvolvimento moral, que abrange dimensões psicológicas interdependentes: cognição, emoção e ação. No entanto, algumas questões fundamentais precisam ser mais estudadas e aprofundadas, sobretudo, aquelas relacionadas ao conteúdo das crenças e dos valores morais, assim como a relação entre o social e o moral. A moralidade é um fenômeno social, mas nem todas as questões, regras, crenças e valores sociais são entendidos, ou interpretados, como morais.

Turiel, em seus estudos, indica a precoce distinção feita pelas crianças entre questões "morais" ou puramente referentes à "convenção social" (Turiel, 1998). Em relação a isso, porém, autores como DeVries e Zan (1998) enfatizam a dificuldade para estabelecer uma distinção clara e bem definida entre o social e o moral na maioria das situações. Embora algumas questões possam parecer especificamente questões de convenção social, elas podem ter implicações morais subjacentes ou podem tornar-se morais em determinado contexto interativo. Podemos encontrar um exemplo comum da ambigüidade existente na hora de categorizar como socialconvencional ou moral um determinado comportamento na falta de acordo quanto ao tema da polidez. O fato de dizermos "por favor" ou "obrigado" pode ser considerado por alguns como modos polidos que refletem respeito e, portanto, é uma questão de moralidade, por outros, pode ser considerado como uma questão de mera convenção social acerca do que são boas maneiras em determinada cultura (DeVries \& Zan, 1998).

Aqui, cabem algumas questões importantes para o estudo do desenvolvimento moral. Podemos, de fato, estabelecer uma definição clara e bem definida entre o social-convencional e o moral? Podemos pensar os comportamentos 
sociais à margem das crenças e valores morais do indivíduo, mesmo quando esses comportamentos sejam mais convencionais do que morais? Podemos analisar essas duas dimensões do comportamento humano de forma separada?

Rey e Martínez (1989), ao criticar os enfoques fragmentadores do comportamento humano, enfatizam a necessidade de analisar os comportamentos sociais levando em conta a condição moral geral de quem os expressa, em função da integridade do sujeito. Os autores exemplificam esta questão por meio de um comportamento polêmico: o preconceito racial. Para eles, o preconceito racial não pode ser visto como um comportamento social isolado da condição moral geral de quem o expressa. O racismo, explícita ou implicitamente, pressupõe a existência de superioridade de uns sobre os outros, o reconhecimento de que uns têm mais direitos que os outros. Portanto, o racismo como preconceito pode atuar como indicador geral do desenvolvimento moral do indivíduo, não apenas designando um tipo de relação social entre as pessoas.

Outros autores, como Staub (1991), ressaltam a natureza também multideterminada de comportamentos pró-sociais (como o altruísmo) e anti-sociais (agressão hostil, por exemplo). Para o autor, esses comportamentos não podem ser analisados de forma isolada, uma vez que estão relacionados com vários aspectos psicológicos, como as orientações morais do sujeito e suas características individuais, constituídas no decorrer de seu desenvolvimento. Por outro lado, as orientações ou motivações do indivíduo não determinam por si só o comportamento, uma vez que a motivação se sustenta em uma série de características que são essenciais para que ela se expresse na ação do indivíduo. Dentre essas características, o autor ressalta aquelas que estão relacionadas com o autoconceito, com a autoestima, com as possibilidades de reconhecer as necessidades do outro, e com características específicas do contexto.

\section{Comunicação e metacomunicação no desenvolvimento moral}

Uma vez que a perspectiva sociocultural construtivista enfatiza a natureza social do desenvolvimento, também destaca o papel dos processos comunicativos na transmissão de crenças e valores sociais. Assim, é importante abordar o caráter multifuncional da comunicação, como apontado por Fatigante, Fasulo e Pontecorvo (2004).

As autoras, partindo dos três níveis de abstração da comunicação, apontados por Bateson em 1972, apresentam o conceito de metacomunicação e sua evolução teórica. Trata-se de um conceito primeiramente utilizado no campo da psicopatologia, que parte de uma conceitualização de três níveis de abstração presentes na comunicação humana. $\mathrm{O}$ primeiro nível, denotativo, refere-se às etiquetas aplicadas aos objetos; o segundo, metalingüístico, no qual o objeto do discurso é a linguagem em si mesma; e o terceiro nível, a metacomunicação, no qual o objeto do discurso é a relação entre os participantes da interação.

Sendo assim, metacomunicação significa comunicação sobre a comunicação. Ou seja, é o nível de comunicação que tem como principal objetivo ou função a troca de informações, por parte dos participantes, sobre sua própria interação e/ou relação, e sobre os processos comunicativos referentes a estas interações e/ou relação. Esta função é contínua e pode acontecer tanto pela linguagem verbal como pela linguagem não-verbal (Branco, Pessina, Flores \& Salomão, 2004). Os participantes da interação não só usam signos lingüísticos, mas especialmente utilizam formas não-verbais de ação, como gestos, posturas e movimentos corporais, o ritmo da fala, entonação da voz, olhares e expressões faciais. Todos esses elementos têm um papel preponderante na atribuição de sentido à comunicação e, ao mesmo tempo, são fatores muito importantes para a interpretação de mensagens e a co-regulação das ações dos participantes.

As mensagens metacomunicativas estão estreitamente relacionadas com o tipo de atividade ou contexto em que os participantes da interação estão envolvidos em um momento específico, e com os diferentes papéis que os participantes assumem durante a interação, passando particularmente pelas relações de poder que se estabelecem durante o processo interativo. As mensagens metacomunicativas não só contextualizam a interação, elas também definem como os padrões comunicativos se ajustam às orientações para objetivos dos participantes. Com isso, permitem que novas orientações para objetivos emerjam durante a interação.

A metacomunicação está sempre presente na interação humana, pois existe de forma contínua em nível não-verbal quando as pessoas estão em 
interação (Branco et al., 2004). Eventualmente, se dá de forma verbal (metacomunicação verbal), quando, por exemplo, alguém diz ao colega "Vejo que você se aborreceu comigo!". É a metacomunicação que nos leva à impossibilidade de não existir comunicação entre os seres humanos, mesmo quando entre eles há silêncio e posturas estáticas, como apontado por Salomão (2001).

A metacomunicação constitui-se em um nível do fenômeno comunicativo que se interrelaciona com os demais, uma vez que a comunicação propriamente dita consiste em um processo integrado e complexo. No entanto, a relação ou articulação entre os diferentes níveis pode ser ambígua e/ou contraditória. Essa ambigüidade e/ou contradição entre os níveis da comunicação são elementos fundamentais da comunicação, e quando ligados a padrões patológicos de relações entre as pessoas, podem se constituir em sérios problemas para os indivíduos em interação (Branco \& Valsiner, 2004).

As crianças, assim como todos nós, são altamente sensíveis aos sinais metacomunicativos, incluindo-se as ambigüidades e contradições que freqüentemente existem entre a mensagem e a metamensagem direcionadas a elas pelos colegas e adultos. Particularmente estes últimos, diretamente responsáveis por sua educação e desenvolvimento, devem, pois, ter consciência da qualidade da comunicação que com elas estabelecem, evitando ativamente a configuração de relações de duplo vínculo ou de dupla mensagem - ambigüidade ou ambivalência - com as crianças.

A importância das mensagens metacomunicativas para o desenvolvimento moral é ressaltada por diversos autores de diferentes formas. Para DeVries e Zan (1998), os professores comunicam continuamente mensagens sociais e morais tanto quando dissertam para as crianças sobre regras e comportamentos, como quando administram determinadas sanções para o comportamento delas. Segundo as autoras, essas mensagens fazem parte do ambiente sociomoral da sala de aula, o qual se constitui, na maioria das vezes, em um currículo oculto. É um currículo oculto e desconhecido para os professores que não estão conscientes do ambiente sociomoral que oferecem; no entanto, é menos oculto para as crianças que vivenciam na prática a pressão social que existe na sala de aula.

Salomão (2001) realizou um estudo sobre comunicação e metacomunicação na co-construção de crenças e valores sociais no contexto de interações professora-alunos. A autora analisou as interações de uma professora com seus 26 alunos de primeira série, identificando a presença constante de um padrão comunicativo e metacomunicativo de contradição e ambigüidade, que impedia a clareza e o desenvolvimento de padrões de interação e motivação sociais mais saudáveis, consistentes e autônomos entre as crianças. Mesmo nos momentos em que a professora teve como objetivo promover a cooperação entre as crianças, em suas mensagens metacomunicativas prevalecia a promoção do individualismo e da competição entre as crianças como principal tendência canalizadora.

Tappan (1992) aborda a importância da comunicação para o desenvolvimento moral desde outra perspectiva. A partir de várias idéias desenvolvidas por Vygotsky e Bakhtin sobre o papel da linguagem no desenvolvimento, o autor diz que o desenvolvimento do funcionamento moral é mediado pela linguagem, na forma de diferentes "vozes morais" ou "linguagens morais", provenientes do contexto sociocultural no qual o indivíduo vive. Essas vozes e linguagens morais se originam nas interações da criança com outras pessoas, especialmente com aquelas que cuidam dela. Conseqüentemente, os adultos (em especial pais e professores) devem ter consciência de como as mensagens que comunicam à criança podem transmitir e perpetuar normas culturais nocivas, estereotipias e ideologias. Os adultos devem estar conscientes do poder de suas vozes e de como elas influenciam o funcionamento moral das próximas gerações.

Pode-se concluir, portanto, que a linguagem ocupa um papel fundamental para a compreensão da dimensão psicológica da experiência moral. A linguagem representa a realidade psicológica e, ao mesmo tempo, participa de sua própria constituição. Assim, o estudo da narrativa do indivíduo permite compreender como a linguagem configura o universo moral, constituindo seu perfil e funcionamento (Martins \& Branco, 2001).

\section{Educação e desenvolvimento moral}

As contribuições de vários autores sobre a relação entre desenvolvimento moral e educação têm sido diversas e muito importantes. As autoras DeVries e Zan (1998), seguindo as idéias de Piaget sobre o desenvolvimento do juízo moral, apontam que o desenvolvimento moral acontece no marco das 
relações e interações das crianças com seus colegas e com os adultos responsáveis por elas. Para elas, o ambiente sociomoral colore cada aspecto do desenvolvimento, uma vez que ele é o contexto no qual as crianças constroem suas idéias e sentimentos sobre si mesmas, sobre o mundo das pessoas e dos objetos. Dependendo da natureza do ambiente sociomoral, a criança aprende que o mundo das pessoas é coercitivo ou cooperativo, satisfatório ou insatisfatório. $\mathrm{O}$ ambiente sociomoral se refere à rede de relações interpessoais que forma a experiência da criança, que se configura em dois aspectos principais: a relação adulto-criança e a relação criança-criança. A relação adulto-criança é fundamental, uma vez que é o adulto quem possui a voz dominante na determinação da natureza do ambiente sociomoral da criança pequena, por meio das interações diárias. Nesse sentido, as autoras enfatizam a necessidade de refletir sobre a natureza do relacionamento dos adultos com as crianças, sobretudo, em relação ao exercício de poder por parte do adulto, que muitas vezes é desnecessário e retarda o desenvolvimento da moralidade autônoma.

Puig (1998) propõe pensar na construção da personalidade moral e não em uma educação moral, entendida como simples adaptação social, ou como desenvolvimento da capacidade de juízo moral sobre comportamentos, vícios e determinadas virtudes. Para o autor, a moral não é dada de antemão, nem escolhida casualmente. A moral exige um trabalho de elaboração pessoal, social e cultural, pelo que não é uma construção solitária, é uma tarefa ampla de cunho social que conta com a participação ativa de cada sujeito. Sendo assim, o autor ressalta que os processos de construção moral não podem se basear exclusivamente na aquisição de conhecimento informativo sobre problemáticas sociais e morais, mas no trabalho com os pequenos e grandes problemas morais da experiência humana. Problemas morais que devem ser analisados pessoal e coletivamente, na tentativa de entendê-los melhor $\mathrm{e}$, às vezes, de resolvê-los, embora sua solução não seja definitiva. Para o autor, a intervenção educativa a partir de uma perspectiva que entenda a educação moral como construção da personalidade deve levar em conta a vida, ou seja, as situações produzidas na realidade social. Situações claramente educativas, porém não necessariamente escolares.

A psicologia cultural enfatiza, também, que o desenvolvimento moral se dá a partir da vivência concreta da pessoa no contexto de práticas culturais específicas e do dia-a-dia, em situações educativas não necessariamente escolares. Além disso, ressalta a participação ativa e conjunta do sujeito no seu próprio processo de desenvolvimento moral (Rogoff, 2005). Ou seja, não há um educador ativo e um educando passivo. A participação orientada pressupõe a atividade conjunta de educadores e educandos e tem como objetivo principal enfrentar de forma compartilhada as tarefas morais que surgem, de forma natural, na experiência dos indivíduos.

A perspectiva sociocultural construtivista propõe a integração dessas idéias e destaca o papel constitutivo da linguagem e do afeto para o desenvolvimento moral, assim como a importância do contexto sociocultural em que o indivíduo se desenvolve (Martins \& Branco, 2001). O desenvolvimento moral é, pois, um fenômeno que envolve a inter-relação de aspectos culturais, cognitivos, afetivos e sociais da subjetividade humana e essa complexidade deve ser levada em conta na hora de refletir sobre a relação entre educação e desenvolvimento moral.

As relações e interações das crianças com colegas e com adultos são fundamentais, uma vez que é no marco dessas interações e relações que as crenças e valores morais são transmitidos e ativamente processados pela criança. Portanto, características, conteúdo e qualidade dessas interações e relações são aspectos fundamentais para o processo educativo e, conseqüentemente, para o desenvolvimento moral (Shweder \& Much, 1987). Cabe ao adulto não só refletir criticamente sobre a forma como interage e se relaciona com a criança, mas também sobre a maneira como estrutura as possibilidades de participação da criança no seu próprio desenvolvimento moral. A perspectiva sociocultural construtivista destaca, em especial, a análise da forma com que as pessoas comunicam e metacomunicam as crenças e valores morais que fazem parte de sua cultura pessoal e da cultura coletiva, nas atividades e rotinas do dia-a-dia. Comunicação e metacomunicação que muitas vezes se contradizem, gerando ambigüidades. O conteúdo das crenças e valores morais, assim, deve ser alvo de reflexão e crítica por parte do adulto.

\section{Considerações finais}

O objetivo principal deste trabalho foi abordar o desenvolvimento moral a partir dos pressupostos e conceitos teóricos da perspectiva sociocultural construtivista, buscando contribuir com novas perspectivas de análise para o estudo e 
compreensão de um tema central do desenvolvimento humano, sem deixar de mencionar diversos autores que vêm se dedicando ao estudo deste ponto, mesmo a partir de outras perspectivas teóricas.

Como apontado por Martins e Branco (2001), o estudo do desenvolvimento moral no contexto sociocultural construtivista não adota categorias estáticas e universais, mas também não advoga um relativismo cultural radical. As categorias utilizadas devem, portanto, contemplar sempre o caráter complexo e dinâmico dos fenômenos ligados à vida moral do sujeito, que vive e se desenvolve em contextos específicos.

A perspectiva sociocultural construtivista aponta aspectos fundamentais para o estudo e compreensão do desenvolvimento moral. O primeiro deles é a importância das interações sociais, uma vez que é por meio da relação com outros sujeitos que a criança elege valores, regras e normas que direcionarão seu comportamento moral. $\mathrm{O}$ segundo refere-se ao papel da cultura no desenvolvimento humano. A cultura, como afirma Cole (1992), não deve ser entendida como um pano de fundo do desenvolvimento, nem como simples diferenças entre os diversos grupos humanos. A compreensão do papel da cultura no desenvolvimento humano deve partir de uma definição de cultura como meio que abrange a criação e evolução de instrumentos e signos que atuam como mediadores do desenvolvimento humano. $\mathrm{O}$ terceiro aspecto refere-se à participação ativa do sujeito no seu processo de desenvolvimento e no desenvolvimento histórico da humanidade. Participação ativa que perpassa os conceitos e pressupostos de internalização, externalização, cultura coletiva, cultura pessoal e o modelo bidirecional de transmissão cultural. O quarto refere-se à integração sistêmica, dinâmica e complexa entre práticas culturais e as crenças e valores morais no universo motivacional do indivíduo, que estão na base de sua ação. Este último aspecto é uma contribuição significativa para o estudo e compreensão do desenvolvimento moral, que deve ser entendido de forma ampla, uma vez que a questão da moralidade abrange, além de aspectos concernentes à filosofia, antropologia, etc., as dimensões psicológicas interdependentes da cognição, da emoção e da ação intencional.

\section{Referências}

Branco, A. U. (2006). Crenças e práticas culturais: Co-construção e ontogênese de valores sociais. Revista Pro-Posições (UNICAMP), 17(50), 139-155.

Branco, A. U., \& Valsiner, J. (1997). Changing methodologies: A co-constructivist study of goal orientations in social interactions. Psychology and Developing Societies, 9(1), 35-64.

Branco, A. U., \& Valsiner, J. (2004). Communication and metacommunication in human development. Greenwood: Information Age Publishers.

Branco, A. U, Pessina, L., Flores, A., \& Salomão, S. (2004). A sociocultural constructivist approach to metacommunication in child development. In A. U. Branco, \& J. Valsiner (Org.). Communication and metacommunication in human development. (pp. 3-31). Greenwood, CT: Information Age Publishers.

Cole, M. (1992). Culture in development. In M. H. Bornstein, \& M. E. Lamb (Org.). Developmental psychology: An advanced textbook (pp. 731-788). Hillsdale.: Lawrence Earlbaum Associates.

DeVries, R., \& Zan, B. (1998). A ética na educação infantil: $O$ ambiente sócio-moral na escola. Porto Alegre: Artes Médicas.

Fatigante, M., Fasulo, A., \& Pontecorvo, C. (2004). This is not a dinner: Metacommunication in family dinnertime conversations. In A. U. Branco, \& J. Valsiner (Org.). Communication and metacommunication in human development. (pp. 33-81). Greenwood, CT: Information Age Publishers.

Freitag, B. (1997). Itinerários de Antígona: A questão da moralidade. Campinas: Papirus.

Hoffman, M. L. (2000). Empathy and moral development: Implications for caring and justice. New York: Cambridge University Press.

Lapsley, D. K., \& Narvaez, D. (2004). Moral development, self, and identity. Mahwah: Lawrence Erlbaum Associates. 
La Taille, Y. de. (1992). O lugar da interação social na concepção de Jean Piaget. In Y. de. La Taille, M. K. Oliveira, \& H. Dantas. Piaget, Vygotsky, Wallon: Teorias psicogenéticas em questão. (pp. 11-21). São Paulo: Summus.

La Taille, Y. de. (2006). Moral e ética: Dimensões intelectuais e afetivas. Porto Alegre: Artmed.

Lourenço, O. M. (1998). Psicologia de desenvolvimento moral: Teoria, dados e implicações. Coimbra, Portugal: Livraria Almeida.

Lustosa, A. V. (2005). A compreensão da moralidade: Contribuições teóricas da psicologia do desenvolvimento. In: M. A. Dessen, \& A. L. Costa Jr. (Org.). A ciência do desenvolvimento humano: Tendências atuais e perspectivas futuras. (pp. 249-263). Porto Alegre: Artmed.

Madureira, A. F., \& Branco, A. U. (2005). Construindo com o outro: Uma perspectiva sociocultural construtivista do desenvolvimento humano. In M. A. Dessen, \& A. L. Costa Jr. (Org.). A ciência do desenvolvimento humano: Tendências atuais e perspectivas futuras. ( $p p$. 91-109). Porto Alegre: Artmed.

Martins, L. C., \& Branco, A. U. (2001). Desenvolvimento moral: Considerações teóricas a partir de uma abordagem sociocultural construtivista. Psicologia: Teoria e Pesquisa, 17 (2), 169-176.

Melo, C. D. (1996). Crenças maternas sobre desenvolvimento e educação da criança em contexto de baixa renda. Dissertação de Mestrado, Instituto de Psicologia da Universidade de Brasília, Brasília.

Palmieri, M. W. A. (2003). Cooperação, competição e individualismo: Uma análise microgenética de contextos de desenvolvimento na pré-escola. Tese de Doutorado, Instituto de Psicologia da Universidade de Brasília, Brasília.

Palmieri, M. W. A. \& Branco, A. U. (2004). Cooperação, competição e individualismo em uma perspectiva sócio-cultural construtivista. Psicologia: Reflexão e Crítica, 17(2), 189-198.

Piaget, J. (1994). O juízo moral na criança. São Paulo: Summus. (Originalmente publicado em 1932).
Puig, J. M. (1998). A construção da personalidade moral. São Paulo: Ática.

Rey, F. G., \& Martínez, A. M. (1989). La personalidad, su educación y desarrollo. La Habana: Pueblo y Educación.

Rogoff, B. (2005). A natureza cultural do desenvolvimento humano. Porto Alegre: Artmed.

Rossetti-Ferreira, M. C., Amorin, K. S., \& Silva, A. P. S. (2004). Rede de significações: Alguns conceitos básicos. In: M. C. Rossetti-Ferreira, K. S. Amorin, A. P. S. Silva, \& A. M. A. Carvalho (Org.). Rede de significações: E o estudo do desenvolvimento humano. (pp. 2333). Porto Alegre: Artmed.

Salomão, S. J. (2001). Motivação social: Comunicação e metacomunicação na coconstrução de crenças e valores no contexto de interações professora-alunos. Dissertação de Mestrado, Instituto de Psicologia da Universidade de Brasília, Brasília.

Staub, E. (1991). A conception of the determinants and development of altruism and aggression: Motives, the self, and the environment. In: C. Zahan-Waxler, E. M. Cummings, \& R. Iannotti (Org.). Altruism and aggression: Biological and social origins (pp. 135 -164). Cambridge, UK: Cambridge University Press.

Shweder, R. A., \& Much, N. C. (1987). Determinations of meaning: Discourse and moral socialization. In: W. M. Kurtines \& J.L. Gewirtz (Org.). Moral development through social interaction. (pp. 197-244). New York: Wiley.

Tappan, M. B. (1992). Texts and contexts: Language, culture, and the development of moral functioning. In L. T. Winegar, \& J. Valsiner (Orgs). Children's development within social context. Vol 1. ( pp. 93-117). Hillsdale: Lawrence Earlbaum Associates.

Tugendhat, E. (1997). Lições sobre ética. Rio de Janeiro: Vozes.

Turiel, E. (1998). The development of morality. In W. Damon (Org.). Handbook of child psychology. (pp. 863-93). New York: Wiley. 
Valsiner, J. (1989). Human development and culture: The social nature of personality and its study. Lexington: Lexington.

Valsiner, J. (1994). Bidirectional cultural transmission and constructive sociogenesis. In: W. de Graaf, \& R. Maier (Org.). Sociogenesis reexamined. (pp. 47-70). New York: Springer.

Valsiner, J. (1998). The guided mind: A sociogenetic approach to personality. Cambridge: Harvard University Press.

Valsiner, J. (2007). Culture in minds and societies: Foundations of cultural psychology. New Delhi: Sage.

Valsiner, J., Branco, A. U., \& Dantas, C. (1997). Socialization as co-construction: Parental belief orientations and heterogeneity of reflection. In J. E. Grusec \& L. Kuczynzki (Org.). Parenting and children's internalization of values: Handbook of contemporary theory (pp. 283304). New York: Wiley.

Vygotsky, L. S. (1968). Pensamiento y lenguaje. La Habana: Instituto del Libro. (Originalmente publicado em 1934).

Vygotsky, L. S. (1987). Historia del desarrollo de las funciones psíquicas superiores. La Habana: Científico-Técnica. (Originalmente publicado em 1960).

Vygotsky, L. (1994). The problem of the environment. In R. Van der Deer, \& J. Valsiner (Org.). The Vygotsky reader. (pp. 338-354). Oxford: Basil Blackwell Ltd. 